\title{
Tuberculous retropharyngeal abscess revisited
}

\author{
Eva Menon, Paramita Baruah
}

Department of ENT, University Hospitals of Coventry and Warwickshire, Coventry, UK

\section{Correspondence to} Eva Menon,

evamenon11@hotmail.com

Accepted 19 February 2014
CrossMark

To cite: Menon $\mathrm{E}$, Baruah P. BMJ Case Rep Published online: [please include Day Month Year] doi:10.1136/bcr-2013202514

\section{SUMMARY}

Retropharyngeal tubercular abscess is an uncommon cause of neck pain and dysphagia in the developed world. In this report, we describe an insidiously presenting retropharyngeal abscess treated successfully with intraoral aspiration and antitubercular chemotherapy. A 33-year-old female patient presented with neck pain and dysphagia. MRI revealed a large retropharyngeal abscess that was aspirated intraorally under local anaesthetic. Diagnosis of tuberculosis (TB) was confirmed by positive culture. The patient improved significantly following the initiation of antitubercular therapy. Retropharyngeal abscess is a recognised presentation of TB. The treatment is mainly medical with combination of specific antitubercular antibiotics, and aspiration may be sufficient for abscess drainage.

\section{BACKGROUND}

Over nine million new cases of tuberculosis (TB), and nearly two million deaths from $\mathrm{TB}$, are estimated to occur around the world every year. ${ }^{1}$ The WHO declared TB a global emergency in 1993. In spite of availability of effective antitubercular (anti-TB) antibiotics, TB remains the leading cause of death among curable infectious diseases. ${ }^{1}$ Although classically believed to be a disease of the third world, incidence of TB has risen in the western world. This is partly due to the AIDS epidemic and partly due to increased geographical translocation of the human population. The UK, which represents huge cultural and ethnical variability, currently reports around 9000 cases of TB each year. ${ }^{1}$

TB commonly involves the lungs, but can also affect other parts of the body-otherwise known as extrapulmonary TB. The common sites of extrapulmonary disease include the lymph nodes, osteoarticular areas, abdominal organs and central nervous system. When skeletal TB occurs, it affects lumbar, thoracic and cervical vertebrae in decreasing order of frequency. ${ }^{2}$ In view of its unusual presentation, the diagnosis of extrapulmonary $\mathrm{TB}$ can be difficult and a high index of suspicion is required. Retropharyngeal abscess is a rare presentation of TB and to the best of our knowledge, only two cases were reported in the UK in the past 10 years.

We illustrate a case of TB presenting as a retropharyngeal abscess in a young patient. We discuss the salient features of tubercular retropharyngeal abscess and highlight the importance of maintaining $\mathrm{TB}$ as a differential diagnosis even in developed countries.

\section{CASE PRESENTATION}

A 33-year-old female patient presented to the general practitioner (GP) with an insidious onset of left-sided neck pain. This was preceded by an upper respiratory tract infection associated with flu-like symptoms and myalgia. The neck pain did not settle with conservative measures and 4 months later the patient developed swallowing difficulty and weakness of her left arm. At this point, the GP requested MRI to rule out cervical disc prolapse.

Following MRI, which showed large retropharyngeal abscess, the patient was urgently admitted under the care of neurosurgeons and placed in a Philadelphia collar.

There was no neurological deficit on initial clinical examination; however, the range of neck movement was significantly reduced due to severe pain. It is of note that a large posterior pharyngeal wall swelling was found on oral examination with no imminent airway compromise. The ear, nose and throat team was requested to help in making diagnosis and further management.

\section{INVESTIGATIONS}

An initial MRI revealed a large retropharyngeal abscess with involvement of pre-cervical soft tissues and destruction of $\mathrm{C} 2$ vertebra (figure 1). There were no signs of cord compression; however, radiological findings were highly suggestive of TB.

\section{TREATMENT}

The patient underwent an intraoral aspiration of the retropharyngeal abscess under local anaesthetic and $18 \mathrm{~mL}$ of frank pus was obtained. The pus was

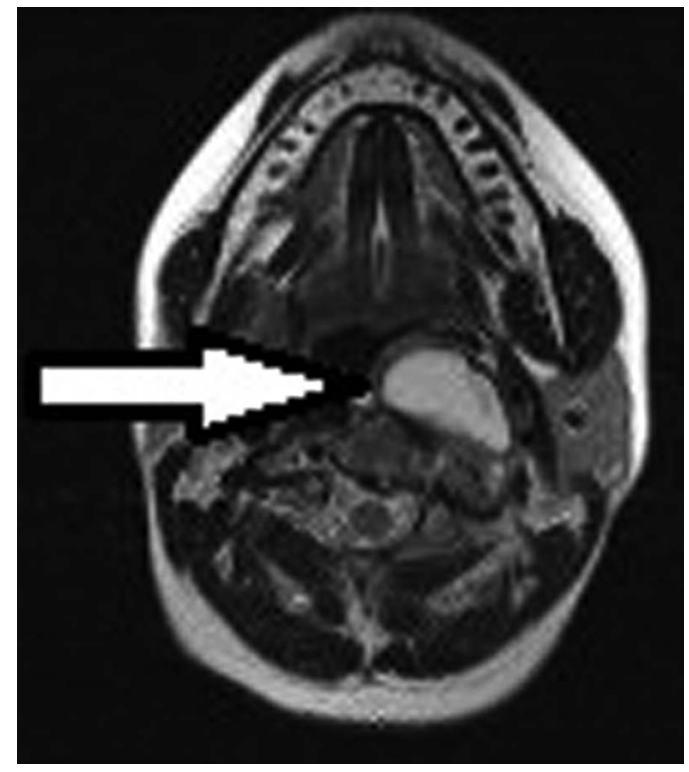

Figure $1 \mathrm{MRI}$ of the neck before the initiation of treatment-axial view. Note the collection in the retropharyngeal space (marked arrowheads). 
sent for microbiology and cytology. There was a significant subjective improvement of symptoms after aspiration of abscess. This was also objectively confirmed by repeat MRI that showed reduction in the size of the abscess.

Owing to the high clinical likelihood of TB, anti-TB treatment was started and continued after the diagnosis was confirmed by positive culture.

The treatment course was stormy as the patient developed intractable nausea and vomiting with the anti-TB regime and required parenteral treatment. The patient sustained a Mallory-Weiss tear, which was managed conservatively. The nausea eventually settled on haloperidol and levomepromazine and the intravenous anti-TB medication was successfully changed to oral medication.

\section{OUTCOME AND FOLLOW-UP}

The patient showed remarkable clinical improvement and was discharged home with oral anti-TB medication 16 days after her admission. Subsequent culture report confirmed the growth of Mycobacterium tuberculosis that was sensitive to the anti-TB drugs the patient was taking. The patient completed a 12-month course of anti-TB therapy which was recommended owing to epidural involvement.

A follow-up MRI performed 6 weeks after discharge showed only a small residual collection. Signs of C1/C2 vertebrae osteomyelitis were still present but no subluxation or vertebral collapse was identified. MRI performed 4 months after her discharge showed almost complete resolution of prevertebral abscess and the cervical osteomyelitis (figure 2). The patient was reviewed by the neurosurgical team 6 months after her discharge and her neck symptoms at that time had improved significantly, except for residual restriction in neck movement to the left. The patient has continued in doing well at 18 months follow-up.

\section{DISCUSSION}

Tubercular retropharyngeal abscess is not commonly reported in the western world. To the best of our knowledge, there are only two cases of retropharyngeal abscess reported in the UK in the

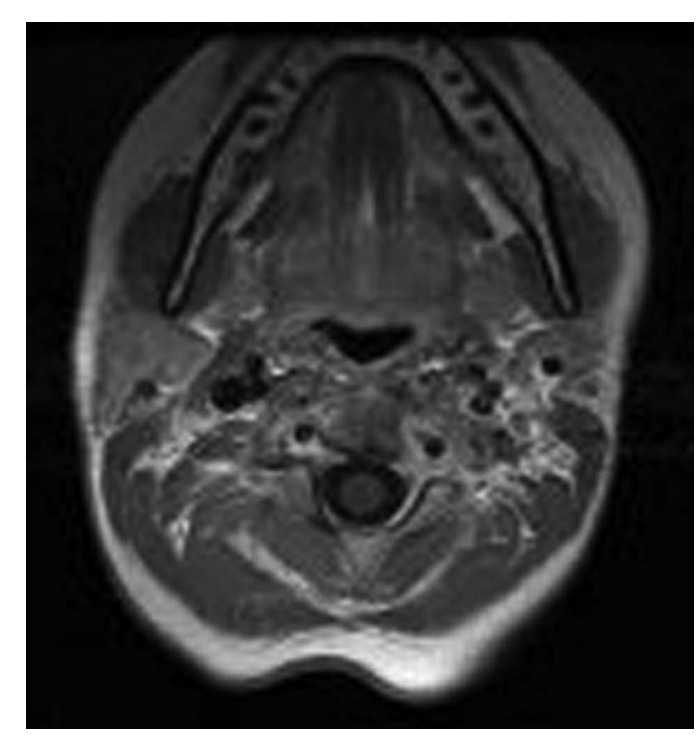

Figure 2 MRI of the neck performed after completion of the treatment-axial view. The collection seen in the pretreatment images has completely resolved. past 10 years. The first case was of an 11-year-old boy who presented with a 4-month history of dysphagia, weight loss and twelfth cranial nerve palsy. ${ }^{3}$ The second case was of a 70-year-old man who presented with a 4-month history of otitis externa and a contralateral facial palsy, with a CT scan revealing large retropharyngeal abscess. Microscopy of the aspirated pus confirmed TB which was also found to be a cause for the longstanding ear infection. ${ }^{4}$

The diagnosis of tuberculous retropharyngeal abscess is based on careful patient's history and examination along with a high index of clinical suspicion. Fever, neck pain and dysphagia should elicit the clinical suspicion of an abscess in the retropharyngeal space which has important anatomic connotations as the retropharyngeal space continues inferiorly into the mediastinum. Thus, early recognition of the condition is essential to prevent serious complications such as mediastinitis and airway obstruction. ${ }^{5}$ The diagnosis of retropharyngeal abscess is further supported by radiological imaging which plays an important role in assessing the extent of the disease and possible damage to important structures such as the cervical spine. A CT scan can accurately differentiate cellulitis from an abscess that needs drainage with a reported accuracy of $89 \% .^{6}$ MRI provides a better delineation of soft tissues in the neck and is very useful in assessing vascular complications such as internal jugular vein thrombosis. ${ }^{\text {? }}$

The diagnosis of $\mathrm{TB}$ is confirmed by culture and direct microscopic examination and finding of acid fast bacilli in the aspirate from the abscess. The latter is a highly specific investigative modality; however, its sensitivity is low. PCR is a sensitive technique to detect Mycobacterium in clinical samples and can also provide information regarding drug-resistant strains. ${ }^{8}$ Currently, newer laboratory tests that can aid the diagnosis of $\mathrm{TB}$, such as interferon- $\gamma$ release assays, are available. These were primarily designed for the diagnosis of latent TB. However, there is evidence in recent literature for and against the use of these tests in the acute setting. ${ }^{9}$

As with any abscess, the mainstay of management of retropharyngeal tubercular abscess is drainage of the pus. Surgical drainage of retropharyngeal abscesses through the oral, cervical and combined oral and cervical approaches has been described. ${ }^{10}$ However, external drainage of tubercular abscess may not always be required. Therapeutic aspiration only with or without ultrasound guidance has been used successfully and can be repeated if necessary. ${ }^{5} 11$ Our patient responded well to intraoral aspiration and anti-TB therapy. The most important step in TB management is early referral to a TB-trained physician and prompt initiation of specific anti-TB antibiotics. ${ }^{12}$ The 'standard recommended regimen' is 6 months of isoniazid and rifampicin, supplemented in the first 2 months with pyrazinamide and ethambutol for pulmonary TB. ${ }^{13}$ For extrapulmonary TB including bone involvement, the recommended duration of anti-TB medication is $9-12$ months. ${ }^{14}$

\section{Learning points}

- Retropharyngeal abscess is an uncommon but well-recognised presentation of extrapulmonary tuberculosis.

- Treatment is mainly medical and abscess drainage can be achieved with aspiration.

- A high index of suspicion is necessary to make the diagnosis. 
Acknowledgements The authors would like to thank professor $\mathrm{H}$ Mehanna for his supervision and valuable comments, and University Hospitals of Coventry and Warwickshire for their support and help.

Contributors EM contributed towards the article by writing a preliminary manuscript and PB focused mainly on manuscript editing. The literature search/ review was done by both the authors independently.

\section{Competing interests None.}

Patient consent Obtained.

Provenance and peer review Not commissioned; externally peer reviewed.

\section{REFERENCES}

1 http://www.hpa.org.uk/Topics/InfectiousDiseases/InfectionsAZ/Tuberculosis/

2 Panduranga Kamath M, Bhojwani KM, Kamath SU, et al. Tuberculous retropharyngeal abscess. Ear Nose Throat J 2007;86:236-7.

3 Gunawardana SS, Earley AR, Pollard AJ, et al. Twelfth nerve palsy due to a retropharyngeal tuberculous abscess. Arch Dis Child 2004;89:579.

4 Agada FO, Sharma R, Makura ZG. Atypical presentation of cutaneous tuberculosis and a retropharyngeal neck abscess. Ear Nose Throat J 2006;85:60-2.
5 Mizumura K, Machino T, Sato Y, et al. Tuberculous retropharyngeal abscess associated with spinal tuberculosis well controlled by fine-needle aspiration and anti-tuberculous chemotherapy. Intern Med 2010;49:1155-8.

6 Miller WD, Furst IM, Sandor GK, et al. A prospective, blinded comparison of clinical examination and computed tomography in deep neck infections. Laryngoscope 1999;109:1873-9.

7 Gidley $\mathrm{P}$, Ghorayeb B, Stiernberg C. Contemporary management of deep neck space infections. Otolaryngol Head Neck Surg 1997;116:16-22.

$8 \mathrm{Xu} \mathrm{HB}$, Jiang RH, Sha W, et al. PCR-single-strand conformational polymorphism method for rapid detection of rifampin-resistant mycobacterium tuberculosis: systematic review and meta-analysis. J Clin Microbiol 2010;48:3635-40.

9 Denkinger CM, Dheda K, Pai M. Guidelines on interferon- $\gamma$ release assays for tuberculosis infection: concordance, discordance or confusion? Clin Microbiol Infect 2011;17:806-14.

10 Schuler PJ, Cohnen M, Greve J, et al. Surgical management of retropharyngeal abscesses. Acta Otolaryngol 2009;129:1274-9.

11 Attia M, Harnof S, Knoller N, et al. Cervical Pott's disease presenting as a retropharyngeal abscess. Isr Med Assoc J 2004;6:438-9.

12 http://publications.nice.org.uk/tuberculosis-cg117 (NICE guidelines 2011).

13 Nalini B, Vinayak S. Tuberculosis in ear, nose and throat practice: its presentation and diagnosis. Am J Otolaryngol 2006;27:39-45.

14 Treatment of tuberculosis: guidelines 4th edition. WHO/HTM/TB2009.420:95

Copyright 2014 BMJ Publishing Group. All rights reserved. For permission to reuse any of this content visit http://group.bmj.com/group/rights-licensing/permissions.

BMJ Case Report Fellows may re-use this article for personal use and teaching without any further permission.

Become a Fellow of BMJ Case Reports today and you can:

- Submit as many cases as you like

- Enjoy fast sympathetic peer review and rapid publication of accepted articles

- Access all the published articles

- Re-use any of the published material for personal use and teaching without further permission

For information on Institutional Fellowships contact consortiasales@bmjgroup.com

Visit casereports.bmj.com for more articles like this and to become a Fellow 